\title{
Tying the Network Together:
}

\section{Evaluating the Impact of an Intervention into the Advice Network of Public Managers}

\author{
David Lazer \\ Department of Political Science \\ College of Computer and Information Science \\ Northeastern University \\ and \\ Harvard Kennedy School \\ Harvard University \\ Ines Mergel \\ Department of Public Administration \\ Syracuse University
}

\begin{abstract}
Networks are often see as emergent and self managed; and yet much of the research on networks examines how networks affect the effectiveness of systems and individuals. Is it possible to intervene in the configuration of a network to improve how it functions? Here we evaluate the impact of an intervention to change the array of relationships connecting a set of distributed public managers-State Health Officials (SHOs). SHOs were brought together for a one week executive educational program near the beginning of their tenures. This paper evaluates the question as to whether this program had long run effects on the ties among SHOs. Using a combination of survey and interview data, we find that there is a substantial effect on the probability of ties between individuals that attend the program together, relative to individuals who attend the program in different cohorts. Given recent findings that highlight the importance of interpersonal networks in the effectiveness of individual managers, this suggests a potential role for interventions to improve the efficiency of dispersed, public sector manager to manager networks.
\end{abstract}

\section{Keywords:}

Program evaluation, public health networks, informal cross-agency communication, network analysis, qualitative research

Acknowledgements: We gratefully acknowledge the Robert Woods Johnson Foundation (RWJF) for this research. Any opinions, findings, and conclusions or recommendations expressed in this material are those of the authors and do not necessarily reflect the views of the RWJF. 
Can we intervene in the structure of the networks of public sector managers? Networks are often characterized as "organic" "emergent" "grassroots" "bottom up", to be contrasted with "command and control" and "hierarchical". Such an impressive array of adjectives seemingly abhors the possibility of interventions to affect the structure of an interpersonal network, and yet serendipity is surely in part a product of design (or, as Branch Rickey would state: Luck is the residue of design.). In fact, we know that institutional and architectural design have profound impacts on network structure, where, for example, the probability of a tie between two people in an office drops off exponentially with physical distance (Allen, 1977), and that organizational silos are typically reflected in the structural holes within organizations (Burt, 1992).

The possibility of effective intervention in the structure of inter-managerial networks in the governing system of the United States is intriguing for several reasons. As Brandeis pointed out long ago, the potential genius of the decentralized federal system is that it allows for innovation at the periphery to gently diffuse across the country. Presumably interpersonal networks are one mechanism for this diffusion—especially for the multitude of small managerial innovations that would not receive attention more broadly. A considerable accumulation of research over the last decade (e.g., O'Toole Jr, 1997; L. J. O'Toole \& Meier, 2004) highlights how the network of an individual manager might affect their effectiveness. A demonstration that a system-wide intervention could have an impact on the structure of the network should therefore be of general interest.

Here we evaluate the impact of a particular, accidental, intervention in the network of State Health Officials (SHOs). A SHO is the official in charge of managing 
health related policy in each state. In 1998, the Robert Woods Johnson Foundation (RWJF) funded a program, the State Health Leadership Initiative (SHLI), that aimed at arming SHOs at the beginning of their tenure with policy and managerial knowledge to help them be more effective. This program was based on a traditional human capital paradigm: provide knowledge at a one-week training session that would subsequently prove useful to these managers. These sessions also created an accidental intervention in the networks of these managers, where that session provided an opportunity to form relationships with other SHOs from which they might subsequently draw resources. We take this as a natural (quasi)experiment, and evaluate whether this intervention did subsequently affect the probability of information exchange among the participating SHOs. 


\section{Studying networks in the public sector}

The notion that informal connections play a key role in the functioning of US government has a long history in the study of federalism. It is only in the last decade or

so that networks have received more formal attention. O'Toole (1997:45) defined as networks "structures of interdependence involving multiple organizations or parts thereof, where one unit is not merely the formal subordinate of the others in some larger hierarchical arrangement." Most of the subsequent empirical research in Public Administration has focused on interorganizational collaborative networks and the measurement of networks for service delivery (Milward \& Provan, 1998), performance of managers within public sector networks based on their structural positions to exploit opportunities (see for example: Agranoff \& McGuire, 2001; Jackson \& Stainsby, 2000; Meier \& O'Toole, 2005; Laurence J. O'Toole \& Meier, 1999; L. J. O'Toole \& Meier, 2004; Provan \& Milward, 2001), general governance issues in policy making (Klijn \& M., 2000), or interaction processes within government as a network actor.

There has been relatively little research on the role of informal relationships and inter-organizational knowledge sharing, our focus here, in the literature on public organizations. There has been, however, an explosion of research on inter-organizational knowledge sharing in the private sector, with a particular focus on the hightech industry (Powell, 1990). This research suggests (for example) that not all information and knowledge required to pursue an organization's goals are readily available within the organizational boundaries (Anand, Glick, \& Manz, 2002; Grant, 1996). Therefore, members of an organization often rely on knowledge from external third parties (Anand, 
et al., 2002). One popular source for tapping into external knowledge is that of networks of professionals who share similar occupations and have experience in similar fields.

For the purpose of this paper, we refer to networks of professionals and peer networks in a broad sense, defining them as a set of loosely coupled relationships that serve as bridges across formal organizational boundaries (Brown \& Duguid, 2000, 2001). They emerge from connections professionals establish among each other to share common practices and to support the knowledge flows within their overall community. Networks of professionals help to access knowledge to conduct the tasks within a professional environment that is not accessible in codified form, such as handbooks, training manuals or through existing reporting and hierarchical structures. In fact, knowledge is more complex and based on experience (Cross, Rice, \& Parker, 2001; Kram \& Isabella, 1985; Morrison, 2002). It is therefore difficult to transfer knowledge and experiences from one individual to another. Research has shown that the transfer mostly occurs through informal processes such as socialization and internalization (Morrison, 2002; Nonaka \& Takeuchi, 1995, 1996).

Given the apparent utility of effective knowledge sharing, it would seem certain there would be extensive evaluations of the impact of interventions to that end. While there has been research that has studied interventions meant to instigate knowledge sharing (Wenger \& Snyder, 2000), there have been few or no attempts to evaluate the impact of those interventions relative to a counterfactual of no intervention in either the private or public sector. Such an evaluation can pose many inferential challenges, although these challenges are necessarily embedded within a particular context. Since it is our objective to conduct such an evaluation, we first turn to a discussion of the context 
in which we conducted our analysis, and then to the challenges of inferring a programmatic impact.

\section{Context}

The Robert Woods Johnson Foundation created a program in 1998, the State Health Leadership Initiative (SHLI), with the objective to accelerate the development of leadership capacity of newly appointed State Health Officials (SHOs) to build their personal skills and provide them with adequate knowledge to ensure the effectiveness of the public health system in a rapidly changing health care and political environment (see: http://www.statepublichealth.org/). The SHO in each state is the manager who is responsible for all public health issues. Each year there are about 10 new SHOs who are typically appointed by the governor.

The professional background of SHOs is relatively diverse. Some have extensive experience as public health administrators, such as hospital administrators, or even as alumni SHOs from other states. Some are MDs, others nurses, others Masters in Public Health. Some have devoted their careers to public health issues, and others have primarily been involved in delivering health care. SHOs are responsible for an extraordinarily wide ranging portfolio that might include everything from pandemic preparedness to nursing home regulation. In addition to scientific knowledge of public health, they also need expertise in management, communication, and politics. These extensive knowledge needs create potential benefits from information exchange among SHOs. As an illustration of the potential of the type of knowledge exchange we are 
interested in, consider the following statement from an incumbent SHO (quote drawn from one of our interviews):

I had a situation with the EMS system, and I called [another SHO up] and said "the EMS folks here are riled up. He's an emergency medicine doctor... and had headed an EMS system... He said "don't do anything yet. This can get you fired.... You know there's the EMS system, they're connected to the fire chief, there's a fire chief in every legislative district. These people connect, and no matter what the situation is, this could get you fired...."

This SHO went on to discuss how this advice likely saved his job. In short, the existence of this relationship provided enormous value to this individual. Of course, this phone call was part of an ongoing relationship between these two SHOs. We do not examine here how much exchanges like this increase the effectiveness of SHOs, instead we focus on whether the activities connected to SHLI increase the probability of such relationships.

The activities planned as part of the SHLI for new SHOs include orientation visits with each new SHO administered by the Association of State and Territory Health Officials (ASTHO), as well as a mentoring program which pairs SHLI participants with an experienced colleague who serves as a mentor during the first year of his or her tenure. ${ }^{1}$ In addition, SHOs have the opportunity to participate in two SHLI networking meetings. The largest component of SHLI, and the activity we focus on here, is a weeklong seminar at Harvard University aimed at developing effective leadership and communications strategies.

\footnotetext{
${ }^{1}$ A separate analysis suggests that the mentoring program had a relatively minor impact on the network of SHOs (REFERENCE OMITTED).
} 


\section{Methodology}

This evaluation boils down to a simple question: did participating in SHLI together increase the probability of a tie between two SHOs? In the ideal (hypothetical) research design world we would randomly select SHOs over a series of years to participate in the program, and compare them to SHOs who were not invited to participate, and evaluate whether there were a difference between the treatment and control groups in terms of connectedness. In the second best case we would capture network data over a series of years, pre and post SHLI, and evaluate whether the network among SHOs was denser during the SHLI years.

However, neither approach was possible in this case, because the evaluation was conducted about a decade after the program began. ${ }^{2}$ We therefore adopted a two pronged evaluation strategy. A quantitative quasi-experimental design based on surveys of current SHOs aimed at a standard quantitative evaluation of the impact of the program, and a qualitative study of the processes of knowledge sharing based on interviews of current SHOs. We discuss each in turn.

\section{Quasi-experimental design}

Our basic unit of analysis is the dyad: do two SHOs report sharing information with one another? We therefore surveyed all SHOs regarding their ties to one another. We had four network questions: Among the following SHOs, who do you turn to for information...

1) in general, and specifically about

\footnotetext{
${ }^{2}$ We did attempt collection of retrospective social network data from SHOs dating to prior to 1998, but, unsurprisingly, the response rate was too low to be useful.
} 


\section{2) pandemic preparedness}

\section{3) media relations}

4) personal professional development.

The respondents were provided a full roster of current SHOs, and asked to indicate with whom they had which type of relationship. The total number of SHOs included was 57 $(\mathrm{N})$, which represents the whole population of current State Health Officials in all states and territories. There were 37 responses, yielding an overall response rate of $64 \%$, or $73 \%$, if territories and SHOs that were replaced during our data collection are omitted $(\mathrm{N}=37){ }^{3}$ In addition to the network survey, we also collected attribute data on career (prior professional positions and career pathways), tenure, and gender.

The inferential challenge in quantitatively evaluating the impact of SHLI, given that all current SHOs had the opportunity to participate in the program, is to evaluate what would have happened if they had not had that opportunity. That is, given a treatment seemingly at the systemic level, and the ability only to examine the system while it has been "under treatment" how do we evaluate the impact of the treatment?

Here we rely on the fact that our analytic focus is on the dyadic, not systemic level. And there is, in fact, quite a lot of variation at the dyadic level. Some dyads "attended" the one-week SHLI program together and most did not. That is, if Joe and Anne attended the one-week training together, the Joe-Anne dyad received the treatment. In a given year, if 10 people attended SHLI together, that would equal 45 (undirected) dyads that received treatment.

The counterfactual is a bit trickier. The first issue is that a nontrivial number of SHOs did not attend SHLI at all. This might be exogenous (e.g., a random scheduling

\footnotetext{
${ }^{3}$ No territory SHOs answered the survey.
} 
conflict), or endogenous (some SHOs may feel they have little need to learn about their jobs from outsiders). If the choice to attend SHLI is endogenous, then including dyads with individuals that did not attend SHLI in the control group would badly bias the analysis in favor of a positive finding. Thus, while we include such dyads in our analyses below, we view as our counterfactual dyads those dyads where both members attended the week long SHLI course in different years. That is, we compare dyads where both individuals attended SHLI together to dyads where both individuals attended SHLI in different years, inferring that any difference is due to attending SHLI together.

The remaining inferential challenge is whether there are other mechanisms which drive people who became SHOs at about the same time to talk. To deal with this we control for the difference in years for when SHOs started, and explore with the qualitative data whether there is something else that would drive people who started in the same year to be more likely to talk to each other.

\section{Qualitative component of research}

While the emphasis of this paper is on the quantitative analysis, we augment this analysis with qualitative data from a series of structured interviews with the SHOs in order to illuminate the processes by which SHOs formed relationships, when they meet and how they maintain communication across organizational and geographic boundaries . The secondary focus is on the utilization of ties: When do SHOs have the need to reach out to their peers and consult each other. We interviewed 47 current SHOs, which yielded 622 pages of transcribed interview text which was hand-coded using the 
qualitative data analysis software NVIVO (2008). The coding scheme is available in Appendix 1.

\section{Estimation}

To assess the research question about what influences the observed network structure, we applied Multiple Regression with Quadratic Assignment Procedure (MRQAP) to the data. MRQAP is a widely used statistical tool that computes the extent to which different network types are associated to one another and is a statistical method that replaces ordinary regression statistical permutation-based tests of significance (Dekker, Krackhardt, \& Snijders, 2007; Hsu \& Tzeng, 2010; Krackhardt, 1988; Tsai \& Goshal, 1998). The underlying assumption here is that the unit of observation is the dyad and therefore each unit in a dataset may be dependent on other units. In statistical terms, the data are most likely autocorrelated, and this might influence the analysis. For example, in a network matrix, each row is derived from self-reports of one actor representing his perceptions of how often he interacts with the other actors in the organization. Thus, each row in the matrix shows systematic interdependence because it is derived from the same source, which can lead to negatively biased estimates of standard errors and an inference of significant relations between independent and dependent variables where none exists (Krackhardt, 1988). MRQAP tests are robust against a variety of common network autocorrelation structures that do not have to be modeled explicitly, e.g., in other methodological approaches such as p-star (Raider \& Krackhardt, $2001: 69)$.

This procedure requires one-mode, two-way matrices ( $n \times n$ networks) in a square matrix format. In the first step, the MRQAP algorithm performs a standard multiple 
regression across corresponding cells of the dependent and independent matrices. The diagonal values of the matrix are ignored. In the second step, the rows and columns (together) of the dependent matrix are randomly permuted to give a new matrix. This step is repeated arbitrarily hundreds of times in order to estimate standard errors for the regression coefficient. For each coefficient, the proportion of random permutations that yielded a coefficient as extreme as the one computed in step 1 are counted for each coefficient. The result is a distribution of the permuted correlations between the two matrices that is compared to the actual correlation. If, for example, fewer than $5 \%$ of the regression coefficients are larger than the actual correlation, the correlation is considered to be significant at the 0.05 level (one-tailed test).

The dependent variable contains the dataset with the observed data: the matrix, which values are to be predicted. The independent variables are the predictor matrices. To test the null-hypothesis that the social network and the professional network have no influence on the advice network, a K-step-semi-partialing asymptotic procedure was chosen (Everett \& Borgatti, 2002). The matrices were used in their original format and not symmetrized.

The independent matrixes were created by converting single attribute vectors (such as numbers of years in office, a numeric value for each geographic region and the year in which a SHO has participated in the SHLI program) into actor-by-actor relational matrices. As an example, for the treatment matrix (participating in the same cohort in the SHLI) if two members of a dyad participated in the same year in the SHLI program, the matrix cell showed a 1 for their $\mathrm{x}_{\mathrm{ij}}$ values, otherwise a 0 .. This 
procedure allows analysis of whether shared attributes between two actors affect the probability of a tie.

\section{Findings}

Our primary question is whether the SHLI had an impact on the probability of a tie between two SHOs. ${ }^{4}$ The interviews of SHLI participants repeatedly highlighted the importance of the comraderie of the week together at Harvard, where statements by these two SHOs are representative:

I guess the most important thing is the personal relationships. We were able to gel as friends in a small group. I think there were 9 in our group, spending 4 days together, 5 days together. And those people, we still communicate with each other.

I think that getting away for that week, at Harvard, with your new classmates, provides an infrastructure and a cohort of people that come through that have an identity, and a comfort level, and I think that's really important. Even now I look at how many of my classmates are still there. I'd have to do the count, but people identify with their class. It gives them someone that can really help them a lot.

Having forged these relationships at SHLI allows the members of the cohort to call on each other subsequently, as another SHO states:

I think participation in the State Health Leadership Initiative has allowed me to get to know more of the health officials in other states. And so I just naturally turn to them more frequently now. It's a lot easier to pick up a phone and call someone when you know them even minimally, than when you just know them as a name on a sheet a paper.

\footnotetext{
${ }^{4}$ Note elsewhere we analyze the overall structure of the SHO network (REF REMOVED). We find that the network, especially the topic specific ones are quite sparse (as is clear from the above table), centralized, with key dyadic drivers of ties including adjacency of states and common region of the country.
} 
The descriptive statistics from the network survey support the proposition that the program had an impact on the probability of a tie between two SHOs. As noted above, each dyad may be categorized in four ways: (1) where both members of the dyad were in the same SHLI cohort (N (number of dyads) =124), (2) where the members of the dyad belonged to different SHLI cohorts $(\mathrm{N}=428)$, (3) where only one member of the dyad participated in SHLI ( $\mathrm{N}=1,244)$, and (4) neither member of the dyad participated in SHLI $(\mathrm{N}=646) .{ }^{5}$ We view the type 2 dyads as the counterfactual for type 1 dyads. Table 1 summarizes the different densities of ties for each type of dyad.

Table 1: $\quad$ Densities within and across SHLI cohorts

\begin{tabular}{|l|c|c|c|c|}
\cline { 2 - 5 } \multicolumn{1}{c|}{} & $\begin{array}{c}\text { Talk in } \\
\text { general }\end{array}$ & $\begin{array}{c}\text { Media } \\
\text { relations }\end{array}$ & $\begin{array}{c}\text { Pandemic } \\
\text { preparedness }\end{array}$ & $\begin{array}{c}\text { Professional } \\
\text { development }\end{array}$ \\
\hline $\begin{array}{l}\text { Both in SHLI, } \\
\text { same cohort }\end{array}$ & 0.32 & 0.02 & 0.08 & 0.07 \\
\hline $\begin{array}{l}\text { Both in SHLI, } \\
\text { different cohorts }\end{array}$ & 0.10 & 0.02 & 0.04 & 0.03 \\
\hline $\begin{array}{l}\text { One in SHLI, } \\
\text { one not }\end{array}$ & 0.04 & 0.01 & 0.01 & 0.01 \\
\hline Neither in SHLI & 0.02 & 0.00 & 0.01 & 0.01 \\
\hline $\begin{array}{l}\text { Ratio of same cohort to } \\
\text { different cohort }\end{array}$ & 3.3 & 1.5 & 2.3 & 2.8 \\
\hline
\end{tabular}

The descriptive statistics suggest that the SHLI might be having a very large effect on communication among SHOs, with a ratio of same cohort to different cohort of 3.3 for talk in general, and ranging between 1.5 to 2.8 for media relations, pandemic preparedness, and professional development (although it is important to note the very low densities of these latter networks).

\footnotetext{
${ }^{5}$ Note that the number of dyads underlying Table 1 is larger than analyzed for the MRQAP below, because the MRQAP requires dyads in which there are responses from both members of the dyad.
} 
Of course, descriptive data does not convey the statistical significance of these relationships, nor control for any confounders. In table 2 we present the results of the MRQAP analysis. We include four independent variables to estimate tie creation for each of the four networks: (1) years of overlapping tenures for the dyad whether the dyad was in the same SHLI cohort; (2) whether both members of the dyad came from the same geographic region, (3) whether either member of the dyad participate in the same SHLI cohort; and (4) whether both members of the dyad participated in SHLI. ${ }^{6}$

Table 2: $\quad$ Multiple Regression Quadratic Assignment Procedure - MRQAP

\begin{tabular}{|c|c|c|c|c|c|c|c|c|}
\hline \multirow[b]{3}{*}{$\begin{array}{l}\text { Independent } \\
\text { variables }\end{array}$} & \multicolumn{8}{|c|}{$\begin{array}{c}\text { Dependent variables: } \\
\text { Network types }\end{array}$} \\
\hline & \multicolumn{2}{|c|}{ Talk in general $^{\mathbf{1}}$} & \multicolumn{2}{|c|}{ Media relations $^{2}$} & \multicolumn{2}{|c|}{$\begin{array}{c}\text { Pandemic } \\
\text { preparedness }^{3}\end{array}$} & \multicolumn{2}{|c|}{$\begin{array}{c}\text { Professional } \\
\text { development }^{4}\end{array}$} \\
\hline & $\begin{array}{c}\text { Stdized. } \\
\text { Coefficient }\end{array}$ & Significance & $\begin{array}{c}\text { Stdized. } \\
\text { Coefficient }\end{array}$ & Significance & $\begin{array}{c}\text { Stdized. } \\
\text { Coefficient }\end{array}$ & Significance & $\begin{array}{c}\text { Stdized. } \\
\text { Coefficient }\end{array}$ & Significance \\
\hline $\begin{array}{l}\text { Overlap in } \\
\text { tenure }\end{array}$ & -0.013 & 0.420 & -0.013 & 0.409 & 0.012 & 0.344 & 0.002 & 0.446 \\
\hline $\begin{array}{l}\text { Region } \\
\text { overlap }\end{array}$ & 0.147 & 0.001 & 0.147 & 0.001 & 0.122 & 0.001 & 0.049 & 0.041 \\
\hline $\begin{array}{l}\text { Same SHLI } \\
\text { Cohort }\end{array}$ & 0.091 & 0.011 & 0.091 & 0.014 & 0.089 & 0.012 & 0.0549 & 0.048 \\
\hline $\begin{array}{l}\text { SHLI } \\
\text { participation }\end{array}$ & 0.043 & 0.196 & 0.043 & 0.199 & 0.030 & 0.216 & 0.001 & 0.452 \\
\hline
\end{tabular}

1: Adjusted $\mathrm{R}^{2}$ "Talk in general” network $=0.033$

: Adjusted $\mathrm{R}^{2}$ "Media relations" network $=0.033$ $\mathrm{n}=37$ (State Health Officials)

3: Adjusted $\mathrm{R}^{2}$ "Pandemic preparedness" network $=0.024$

\# of permutations: 2,000

": Adjusted $\mathrm{R}^{2}$ "Professional development" network $=0.003$

The analysis in table 2 confirms the statistical significance of belonging to the same SHLI cohort for all four network types. Moreover, the MRQAP calculations also confirm that regional overlap has a highly significant effect on tie creation across all four networks. Serving overlapping terms (tenure overlap) does not seem to have an effect on

\footnotetext{
${ }^{6}$ Inclusion of additional control variables (such as proximity of states, gender of SHOs, etc) did not materially affect the statistical significance of the treatment effects discussed below. Results available upon request.
} 
creating ties among SHOs. Finally, a dyad in which one or both members participated in SHLI, but in different cohorts, is associated with a positive, but marginally statistically significant $(\mathrm{p}<.10)$, increased probability of a tie, which could be consistent with either a selection effect (more sociable SHOs participated in the program, which is consistent with the qualitative data) or a cross cohort treatment effect (for which we find little corroborating evidence).

\section{Discussion and conclusion}

There has been increased attention to the role that networks play in the effective functioning of both public and private organizations. The existence of informal mechanisms of knowledge sharing is especially important when we consider the decentralized system of US government. Standard hierarchical mechanisms of knowledge sharing simply are not applicable in a federal system. This does not mean that interventions in the knowledge sharing process are impossible. The literature on networks thus begs the question: is it possible to intervene in the system so as to increase connectedness?

In order to address this question we examined a particular program $-\mathrm{SHLI}$ - that plausibly would have an impact on the connectedness of a particular set of public officials: State Health Officials. We compared the probability of a relationship between two individuals who participated in same training cohort of SHLI to pairs of individuals who were in different cohorts of SHLI. Our key finding: participating in SHLI together was associated with a statistically and substantively large increased probability of a relationship. 
Further, because the baseline probability of a tie for different regions is so low, SHLI participation is especially important for inter-regional ties, where $16 \%$ of "talk in general" inter regional ties involve dyads that went through SHLI together, whereas this is the case for only $8 \%$ of within region ties. This is important because long distance ties - ties connecting individuals who are not connected through many intermediariesare critical drivers of diffusion of information in systems (Granovetter, 1973; Watts \& Strogatz, 1998).

There are a few caveats to the analysis, of course. On the inferential side, our analysis depends on the assumption that there are not other factors that drive individuals from the same cohort to communicate. This is in part controlled for by including the difference starting years as a control; however, if there is a nonlinearity associated with being of exactly the same cohort this would not suffice. However, concerns in this regard are significantly attenuated because (1) there really do not exist distinct generations of SHOs in the sense that a SHO might be appointed any time during the year, and thus be closer in tenure to someone appointed in an adjacent year-thus in the absence of other institutional mechanisms that group SHOs by year it is hard to justify an expectation of a nonlinear relationship with different in starting years; (2) there was not a single mention in any of the interviews of some institutional mechanism (like a joint orientation process) that would facilitate same cohort tie creation, as compared to repeated mentions of SHLI $^{7}$ and (3) there are no cohort effects for dyads where one or both members did not participate in SHLI. We would argue, therefore, that a causal interpretation is the most plausible explanation for the finding we report.

\footnotetext{
${ }^{7}$ As discussed in REFERENCE REMOVED other factors that were repeatedly mentioned in the interviews include: (1) the role of HHS regional meetings, (2) the need to coordinate some policies with adjacent states.
} 
The second caveat is that while we find large effects, these are large effects relative to low base rates - that is, the density of ties among SHOs is generally fairly low, especially for the more specialized networks. Further, the systemic impact of SHLI is limited due to fact that relatively few dyads were "treated". About $5 \%$ of the dyads we examined in the analysis above involved pairs of individuals who participated in SHLI together. Even among dyads where both members participated in SHLI, less than $25 \%$ involved pairs of individuals from the same cohort. In short, the cohort-based nature of the program intrinsically limited the potential of a wider impact. And further, the ties that were being fostered were among individuals who had the least experience (initially), and thus the least to learn from one another. That is, the program was not optimized to create social capital.

There are also some limitations in external validity, even within the population under study. Specifically, we excluded from the comparison dyads where one or both members did not participate in SHLI. There well may have been an interaction between the treatment and the proclivity to seek treatment. Thus, for example, if you could mandate that every SHO participate in SHLI, one could not extrapolate from these results to individuals who would have chosen not to participate.

Those caveats aside, this is an existential proof of the potential of external intervention to shape the informal networks among state (and likely local) governments. These were sizable effects, likely with systemic consequences, and this points both to the need for further research on when these types of interventions have an impact on tie formation, as well as to interventions in other sectors to facilitate the creation of social capital. 


\section{Appendix 1: : $\quad$ Coding scheme for qualitative interviews}

A. Individual information

- Name

- Position title

- Education

- Career path

- Previous jobs

- Start date as SHO

- Tenure in office

- How did he/she got this job?

- Friend of governor

- Official application

- Someone asked him/her

B. Knowledge sources by topic area

1. Getting up to speed on the new job

- Internal sources

- Staff (in the department)

- Experts (outside the department) / Advisors

- External sources

- Human sources

- Other states

- Mentors

- Former SHOs

- Friends

- Non-human sources

- Handbooks, manuals

- ASTHO

- Secondary data and reports

- Topic areas

- Running the office

- Personnel changes

- Former practices

- Past experience

- Legislature

- How to present self [this might go into the media category]

- Role as SHO/director

- Specific names of SHOs

\section{Pandemic preparedness}

- Internal sources

- Staff

- Other agencies within the same state

- External sources

- Former SHOs

- Internet, web, Google 
- Regional groups

- New England Group of SHOs

- Region 8

- Topic areas

- Names of states within regions

- Bird flu

- Anthrax

- Pandemic pro-planning

- Other public health issues

- Communication

- Frequency

- Channel

- Email

- Phone (conversations)

- Face-to-Face meetings

\section{Dealing with the press}

- Internal sources

- External sources

\section{Dealing with the governor}

- External resources

- ASTHO

- Handbook of the first 100 days

- phone calls with ASTHO

- Day on the Hill

- Names of ASTHO representatives

- Regional representatives: State health officials covering a region

- NGA

- Internal resources

- Staff

- Governor himself

- Ties to Governor

- Prior to appointment

- Friendship

- Worked together

- Not known before

- Current relationship

- How was the SHO appointed?

\section{Professional development}

- Human sources

- Past SHOs

- Mentor(s)

- Formal

- informal

- Non-human sources

- National conferences 
- Regional meetings

- Region 8 meetings

- Names of states

- Rocky Mountain States

- Frequency of meetings

- Meet periodically

- Talk on the phone

- ASTHO annual meetings:

- ASHTO's Day on the Hill, Washington

- ASTHO's committees, SHOs are members, regular phone conferences (every other months, annual meetings):

- NGA - National Governor's association

- $\mathrm{CDC}$

- Academy of Health

- Robert Wood Johnson Foundation

\section{Dealing with legislature}

- Human sources

- Past SHOs

- Non-human sources

C. Relationships to other SHOs

- Creation of relationship

- Maintenance

- No relationships

- Reasons

\section{General search strategies}

1. Where to go first, second, etc. to find information needed to do the job?

- Internal experts

- National partners

- CDC

- $\quad \ldots$

- Former SHOs

2. Content areas

- How to approach certain diseases

- Types of diseases

3. Change of search strategy over time

E. Giving information to others

1. Approached for help

- Yes/no

- By whom

- Friends / Based on previous friendships

- Other SHOs

- Based on title 
- Inside own agency

- Inside own state

- Outside own agency

- Outside state

2. Types of information/knowledge requested

- Complex / Expert knowledge

- Simple

3. Type of question

4. Frequency

- Couple of times per year

5. Form of request

- Media

- Email

- Phone

- $\quad$ Face to face

- Context

- At a conference

6. Reason for request

- Common problem

- Unique problem

- Prior experience

- Faced similar problems in the past

- Reputation

- $\quad$ of being an expert

- Prior relationship

7. Form of response to inquiries

- Media

- Email

- Phone

- Face to face

- Type of response

- $\quad$ Long

- Short

- Written

- Time to response

8. Behavior on listserver

- Response behavior

- Lurker

- Contributor

- Status

- Moderator

- Expert

- Searcher

F. Why people don't share knowledge 
1. Reasons

a. Unique problems

b. Staff has all the knowledge (internal knowledge)

G. Additional needs (improvements)

1. Local email list (not all states, just neighboring states)

2. Networking opportunities

H. Comments about SHLI

1. Positive

2. Negative 


\section{References}

Agranoff, R., \& McGuire, M. (2001). Big questions in public network management research. Journal of Public Administration Research and Theory, 11(3), 295326.

Allen, T. J. (1977). Managing the flow of technology: Technology transfer and the dissemination of technological information within the R\&D Organization. Cambridge, MA: MIT Press.

Anand, V., Glick, W. H., \& Manz, C. C. (2002). Thriving on the knowledge of outsiders: Tapping organizational social capital. Academy of Management Executive, 16(1), 87-101.

Brown, J. S., \& Duguid, P. (2000). The Social Life of Information. Boston, MA: Harvard Business School Press.

Brown, J. S., \& Duguid, P. (2001). Knowledge and organization: A social-practice perspective. Organization Science, 12(2), 198-213.

Burt, R. S. (1992). Structural Holes. Cambridge, MA.

Cross, R., Rice, R. E., \& Parker, A. (2001). Information seeking in social context: Structural influences and receipt of information benefits. Ieee Transactions on Systems Man and Cybernetics Part C-Applications and Reviews, 31(4), 438-448.

Dekker, D., Krackhardt, D., \& Snijders, T. A. B. (2007). Sensitivity of MRQAP Tests to Collinearity and Autocorrelation Conditions. Psychometrika, 72(4), 563-581.

Everett, M. G., \& Borgatti, S. P. (2002). Computing regular equivalence: Practical and Theoretical Issues. In A. Mrvar \& A. Ferliigoj (Eds.), Metodoloski zvezki (Vol. 17, pp. 31-42). Ljubljana: FDV.

Granovetter, M. (1973). The strength of weak ties. American Journal of Sociology, 78(6), 1360- 1380.

Grant, R. M. (1996). Toward a knowledge-based theory of the firm. Strategic Management Journal, 17, 109-122.

Hsu, S.-H., \& Tzeng, S.-F. (2010). A dyadic perspective on knowledge exchange. International Journal of Technology Management 49(4), 370 - 383

Jackson, P. M., \& Stainsby, L. (2000). Managing Public Sector Networked Organizations. Public Money \& Management, January-March, 11-16.

Klijn, E. H., \& M., K. J. F. (2000). PUBLIC MANAGEMENT AND POLICY NETWORKS: Foundations of a network approach to governance. Public Management Review, 2(1), 135-158.

Krackhardt, D. (1988). Predicting with Networks: A Multiple Regression Approach to Analyzing Dyadic Data. Social Networks, 10, 359-381.

Kram, K. E., \& Isabella, L. A. (1985). Mentoring Alternatives: The Role of Peer Relationships in Career Development. Academy of Management Journal, 28(1), 110-132.

Meier, K. J., \& O'Toole, L. J. (2005). Managerial networking - Issues of measurement and research design. Administration \& Society, 37(5), 523-541.

Milward, H. B., \& Provan, K. G. (1998). Measuring network structure. Public Administration, 76(2), 387-407.

Morrison, E. W. (2002). Newcomers' relationships: The role of social network ties during socialization. Academy of Management Journal, 45(6), 1149-1160. 
Nonaka, I., \& Takeuchi, H. (1995). The knowledge-creating company. New York: Oxford University Press

Nonaka, I., \& Takeuchi, H. (1996). The Knowledge-Creating Company: How Japanese Companies Create the Dynamics of Innovation. Long Range Planning, 29(4), 592-592.

NVivo 8 (2008). NVivo qualitative data analysis software (Version 7th). Melbourne: QSR International Pty Ltd.

O'Toole Jr, L. J. (1997). Treating networks seriously: Practical and research-based agendas in public administration. Public Administration Review, 57(1), 45-52.

O'Toole, L. J., \& Meier, K. J. (1999). Modeling the Impact of Public Management: Implications of Structural Context. Journal of Public Administration Research and Theory, 9(4), 505-526.

O'Toole, L. J., \& Meier, K. J. (2004). Desperately seeking selznick: Cooptation and the dark side of public management in networks. Public Administration Review, 64(6), 681-693.

Powell, W. W. (1990). Neither market nor hierarchy: Network forms of organization. In B. Staw \& L. L. Cummings (Eds.), Research in Organizational Behavior (Vol. 12, pp. 295 - 336). Greenwich, CT: JAI.

Provan, K. G., \& Milward, H. B. (2001). Do Networks Really Work? A Framework for Evaluating Public-Sector Organizational Networks. Public Administration Review, 61-4(414-423).

Raider, H., \& Krackhardt, D. (2001 ). Intraorganizational Networks. In J. A. C. Baum (Ed.), Companion to Organizations (pp. 58-74). Oxford, UK: Blackwell.

Tsai, W., \& Goshal, S. (1998). Social Capital and Value Creation. Academy of Management Journal, 41(4), 4640476.

Watts, D. J., \& Strogatz, S. H. (1998). Collective dynamics of 'small-world' networks Nature, 393, 440-442.

Wenger, E. C., \& Snyder, W. M. (2000). Communities of practice: The organizational frontier. Harvard Business Review, 78(1), 139-145. 